\title{
Battlefield between the ears
}

\section{Mind Wars: Brain Research and National Defense \\ by Jonathan D. Moreno \\ Dana Press: 2006.225 pp. $\$ 23.95$}

\section{Charles Jennings}

On an evening in October 2002, a group of armed Chechen separatists overran a Moscow theatre, taking the audience hostage and rigging the building with explosives. After a short stand-off, Russian special forces flooded the building with an aerosol based on the potent synthetic opioid fentanyl and then stormed it. The narcotic was effective in incapacitating the hostage-takers, many of whom were executed on the spot. In the ensuing chaos, however, 117 hostages also died from fentanyl poisoning. They were victims not only of terrorism but also of poor planning: if the opioid antagonist naloxone had been available to rescuers, many of these deaths could have been avoided.

Welcome to the world of Mind Wars and the military application of neuroscience, which is the subject of this fascinating and sometimes unsettling book. As the author Jonathan Moreno reveals, the US military has a longstanding interest in brain research and, as scientific understanding continues to advance, so does its appeal to the national security establishment. The Department of Defense conducts much of its research in secret, and some of it would probably fare poorly in open peer review - for example, the military continued to fund psychic research until 1995 but with an annual research and development budget of at least $\$ 68$ billion, it can presumably afford to leave no stone unturned. Partly because its activities are more visible, Moreno focuses especially on the Defense Advanced Research Projects Agency (DARPA), which supports unclassified academic research with potential military applications. DARPA has a distinguished record of supporting innovation, including the Internet, so its involvement in brain research must be taken seriously.

A key aim for DARPA is to enhance the mental capacity of human warriors, whose brainpower is an ever-increasing bottleneck in an age of high-tech warfare. Brain-monitoring devices could help manage the flow of information delivered to soldiers in combat, and their mental performance might be further enhanced through drugs - an anti-sleep pill, for instance, is a target for the military. More speculatively, prosthetic devices might even allow human operators to control machines directly from the brain, with greater speed and bandwidth than can be achieved through manual controls. Brain-machine interfaces are still in their infancy but are developing fast, thanks in part to DARPA funding most of the leading academic labs in the field.

As the Moscow siege dramatically illustrated, brain science can also be harnessed for direct offensive means - targeting the brains of one's opponents. The US military has a long-standing interest in (supposedly) non-lethal targeting methods, including drugs as well as less conventional approaches such as loud noise and noxious smells (the most potent of which is said to be 'US Government Standard Bathroom Odor').

Another potential application is the field of interrogation. Future advances might allow us to determine through brain scanning whether someone is telling the truth, and perhaps even to devise methods for reducing their ability to lie. The military began investigating candidate 'truth drugs' (including LSD) in the early 1950s, and although the goal remains elusive, it seems sensible to ask what possibilities exist and under what circumstances it would be acceptable to use them.

Moreno is a bioethicist, and a focus on ethical questions runs through the book. Although I found some of his concerns overstated - he worries, for instance, that soldiers would be depersonalized through brain implants, or that advances in neurogenetics will tempt us to breed genetically altered warriors who lack fear - others seem well founded. If military research leads to effective mind-reading techniques, for example, there will inevitably be pressure to extend these to the civil judicial system, which will raise urgent questions about cognitive liberty.

One weakness of the book is that Moreno's treatment of technical issues is sometimes superficial. Some of the ideas discussed here - such as brain scanning at a distance, or memory augmentation through hippocampal implants - fall close to the fine line separating the visionary from the crackpot, and a more critical examination of this border territory would have been welcome. Moreno recognizes the outright nonsense as such, but an over-reliance on popular news stories rather than technical sources sometimes leads him to give outlandish ideas more credence than they deserve.

The book is a fascinating read despite these reservations, but it still left me wondering, is this stuff for real? Moreno implies it is when he writes: "the powers that can...establish a 'neurotechnology gap' between themselves and their adversaries will establish tactical and strategic advantages that can render them dominant in the twenty-first century. I'm no expert on warfare, but this strikes me as hyperbole. As a reality check, I recommend reading Fiasco (Penguin, 2006), Thomas Ricks' devastating critique of the United States' botched war in Iraq, and asking how the outcome could possibly have been changed by the technologies envisaged in Moreno's book. It is not for lack of high-tech weapons that the Iraq war is going so badly, and given America's overwhelming superiority in firepower, it is not obvious how a new generation of brain-based weapons would represent more than an incremental gain.

The leader of the Manhattan project, J. Robert Oppenheimer, once commented that, by unleashing the power of the atomic bomb, the physicists involved had "known sin". The activities described in Mind Wars may seem like a harmless flirtation by Oppenheimer's standard. Yet any academic involvement in military research presents an ethical dilemma, and Moreno's exploration of this theme is one of the most interesting aspects of his book. He is no knee-jerk pacifist: he accepts that military force is sometimes necessary and argues convincingly that contact between military and civilian research is healthier than the alternative of total secrecy. He also acknowledges the 'dual-use' argument that many DARPA-funded programmes have clear civilian pay-offs. Yet by taking military funding, he says, researchers are in some sense accomplices to the perpetuation of what he calls a "national security state", a posture of open-ended militarization supported by a vast budget that, in the view of many critics, bears little relation to the actual threats confronting the United States.

When interviewing neuroscientists for his book, Moreno found many of them reluctant to discuss the issues raised by their involvement with defence-related research. Mind Wars, the first systematic treatment of the topic, should help bring these questions into the open. Charles Jenningsis a consultant based in Concord, Massachusetts. He is a former editor with the Nature journals and a former executive director of the Harvard Stem Cell Institute. Supplementary links for this review are available at www.connotea.org/user/charlesj / tag/"Mind Wars". 